\title{
How Costly Are Labor Gender Gaps? Estimates by Age Group for the Balkans and Turkey*
}

\author{
David Cuberes \\ Clark University
}

\author{
Ana Maria Munoz Boudet \\ The World Bank
}

\author{
Marc Teignier \\ Universitat de Barcelona and BEAT
}

July 19, 2018

\begin{abstract}
In this paper, we use survey data from the Balkan countries and Turkey to document the presence of gender gaps in the labor market and examine its economic consequences in terms of aggregate income per capita. We first show that the percentage of women in the labor force, as well as in the categories of employers and self-employed, are clearly below the corresponding figures for men. These gender inequalities display a slightly negative time trend and are present in all age groups, with the middle-age group displaying the lowest inequality in terms of labor force participation but the largest inequality in terms of employers share. Using a theoretical framework we calculate that, on average, the loss associated with these gaps is about 20 percent of income per capita. Taking into account that the weight of each age group in the total population is different, we find that the aggregate costs associated to each age group are quite similar on average.
\end{abstract}

JEL classification numbers: E2, J21, J24, O40.

Keywords: gender inequality, entrepreneurship talent, factor allocation, aggregate productivity, span of control, Balkans, Turkey.

${ }^{*}$ We would like to thank the editor Josef Brada as well as two anonymous reviewers for their guidance to improve the article. Financial support from the Spanish Ministry of Economy and Competitiveness, Grant ECO2015-66701-R, and Generalitat of Catalonia, Grant SGR2014-493, as well as funding from the World Bank Multi-donor Trust Fund Umbrella Facility for Gender Equality is gratefully acknowledged. All remaining errors are ours. The views expressed here are those of the authors and do not necessarily represent or reflect the views of the World Bank Group. Corresponding author: dcuberes@clarku.edu. 


\section{Introduction}

There is a vast literature documenting the presence of gender gaps in the labor market in both developing and developed countries. Women are often underrepresented in the labor force in general, but especially in high-earnings occupations. ${ }^{1}$ In this paper, we analyze survey data from several countries of the Balkan Peninsula (Albania, Bosnia-Herzegovina, Croatia, Kosovo, Macedonia, Montenegro, and Serbia) and Turkey to provide some descriptive statistics on the degree of gender inequality in the labor market and calculate the impact of these gender gaps on income per capita and productivity using the framework presented in Cuberes and Teignier (2016). We carry out these calculations for our entire sample in two different periods and also for specific age groups in order to study the changes between different cohorts and over the life cycle. This age decomposition is a valuable exercise to facilitate the formulation of effective and more targeted policies to reduce these gaps.

The aforementioned countries represent an interesting group to study because they all belong to the category of middle-income countries and yet they have sizable gender gaps, several of them higher than the ones expected given their current income level. Most of these countries are on the path to European Union integration. In order to join it, candidate countries are required to satisfy minimum requirements in terms of gender equality and, with only Croatia having joined this club so far, the rest of the Balkan countries have made an effort to comply with these rights in recent years. Still, in most cases, promoting gender equality is often seen as a low-priority task, and much more attention has been paid to political and economic issues (European Parliament Think Tank, 2017). These gaps affect many dimensions of women's day-to-day lives. Women have not reached a critical mass of 30 percent in decisionmaking in most countries in the region, the gender pay gap is around 20 percent, and violence against women is unacceptably high, with 1 in 4 women facing violence from their intimate partners (Inter-Parliamentary Union Women in Parliaments Database, March 2018 update.).

The data we examine display an average labor force participation gap in the Balkan countries and Turkey that is almost twice as large in this region than in the EU28 group of countries, and average gender gaps in the share of employers and self-employed workers that are similar to the EU28 ones. In most cases, these gaps have slightly decreased in the periods analyzed. With respect to the age groups, the old-age group displays the largest gap in labor force participation, while the middle display the largest gap in the share of employers and the young in self-employed. When using these gender gaps in our occupational choice model, we find that the average income loss due to all the gender gaps studied is about $20 \%$, while the loss only due to the entrepreneurship gaps is $6 \%$ on average. The explanation is that these restrictions in the choices of women reduce the amount of productive inputs and distort the

\footnotetext{
${ }^{1}$ See the World Development Report 2012 (World Bank, 2012) for a comprehensive review of these and other gender gaps.
} 
allocation of talent in the economy.

To our knowledge, there are very few papers that quantify the macroeconomic effects of gender gaps in the labor market. Cavalcanti and Tavares (2016) construct a growth model based on Galor and Weil (1996) in which there is exogenous wage discrimination against women. Hsieh et al. (2013) use a Roy model to estimate the effect of the changing occupational allocation of white women, black men, and black women between 1960 and 2008 on U.S. economic growth. Finally, in the model summarized in Section 3 of this paper, Cuberes and Teignier (2016) calculate the macroeconomic effects of gender inequality in the labor market using data from the International Labor Organization for a large sample of countries, but they do not include many of the Balkan countries and they study the case of Turkey only in 2010. Moreover, they do not analyze neither the time evolution nor the age group dimension of these gaps. Our paper complements Cuberes and Teignier (2016) in tow ways. First, it focuses on the Balkans and Turkey in recent years, which is an interesting exercise because this region has been understudied at least in regards to this particular topic, in spite of the large observed in these countries. Second, this is the first study that decomposes these gaps and their macroeconomic costs by different age groups, which is relevant to have predictions about the evolution of these gaps in the next few decades. In this regard, the paper fills in an important gap in the literature showing that gender gaps are persistent and affect all age groups similarly, and indicating that policymakers should focus on barriers that affect all women independently of their age.

The rest of the paper is organized as follows. Section 2 documents several gender gaps in the labor market of the eight countries considered in the study. In Section 3, we sketch the general equilibrium occupational choice model proposed by Cuberes and Teignier (2016) and, in Section 4, we calculate the output costs associated with the gaps in two different years. The years used vary across countries due to data availability. Section 4 also carries out this exercise by different age groups. Finally, Section 5 concludes the paper.

\section{Data Description}

In this section we provide some descriptive statistics of the labor market in Albania, Bosnia-Herzegovina, Croatia, Kosovo, Macedonia, Montenegro, Serbia, and Turkey for two recent years. The data used comes from the World Bank ECAPOV, a data repository that harmonizes nationally representative household surveys, which are a combination of household budget surveys (HBS) and Living Standard Measurement surveys (LSMS), as well as Labor Force Surveys. The ECAPOV micro database is managed and harmonized by the Europe and Central Asia Team for Statistical Development (ECATSD) at the World Bank, covering representative household surveys for 29 countries collected by the national statistics institutes. The country-specific data sources are described in the Appendix I. We choose two years 
that are four to nine years apart to have some sense of how these gaps have changed over time, although we acknowledge the fact that this time interval overlaps in some cases with the so-called Great Recession that started in 2007 and that this may somewhat distort our calculations. The first and second columns of Table 2 show the two years used for each country.

\subsection{Calculation of gender gaps}

We calculate gender gaps in labor force participation using the following expression:

$$
L F P_{-} g a p=100 *\left(1-\frac{L_{f}}{L_{m}}\right)
$$

where the subscripts $f, m$ denote females and males, respectively, and $L$ denotes the number of participants in the labor force. For the employers and self-employment gaps, we use a similar formula but we normalize the number of men and women in each occupation by their corresponding labor force participation. For the gender gap in the share of employers we have

$$
\text { Employers_gap }=100 *\left(1-\frac{\frac{E_{f}}{L_{f}}}{\frac{E_{m}}{L_{m}}}\right)
$$

where $E$ stands for the number of employers. The gender gap in the share of self-employed is given by

$$
\text { Self_gap }=100 *\left(1-\frac{\frac{S_{f}}{L_{f}}}{\frac{S_{m}}{L_{m}}}\right)
$$

where $S$ stands for the number of self-employed.

\section{$2.2 \quad$ Aggregate statistics}

As Table 1 shows, the average gap in labor force particpation is almost twice as large in the Balkans and Turkey than in the European Union group of 28 countries (EU28). The gender gap in self-employed is slightly larger in the Balkans and Turkey, while the opposite is true for the gender gap in employers. ${ }^{2}$

The first three plots in Figure 1 show these three gaps in 2010 and correlate them with the country's GDP per capita in that year. ${ }^{3}$ None of the graphs display a clear correlation between the gaps and economic development. In these figures, the filled diamonds represent the Balkans and Turkey and the empty circles are the EU28 countries. As we can see in the first plot, Turkey is a clear outlier in terms of gender gaps in labor force participation, with an astonishing figure of $59 \%$, much higher than the one corresponding to other countries at similar levels of development. The Balkan countries also score high in this gap, especially

\footnotetext{
${ }^{2}$ We exclude Kosovo from this calculation since we do not have data on the three occupations in 2010.

${ }^{3}$ In Appendix II we list the names of the countries corresponding to the abbreviations used here.
} 
Macedonia (37\%) and Bosnia and Herzegovina (35\%). The second plot shows that Turkey and Albania have the largest employers gap in the entire sample (above 80\%). The gap is also remarkably high in Macedonia (65\%). However, this gap is below the sample average in Croatia, Serbia, and especially Montenegro and Bosnia and Herzegovina. The gaps in selfemployment (third plot) are, on average, somewhat higher than in the EU28 group. Croatia is a clear outlier here, with a very low gap, while Montenegro is the country with the highest gap among the Balkan countries.

The fourth plot of Figure 1 uses data from the World Value Surveys (WVS) to measure how much women's rights are protected in each country. ${ }^{4}$ In particular, we use information on the question: "If jobs are scarce, men should have more right to work than women." WVS calculates the fraction of the population who agrees with this statement, with 5 indicating a strong agreement and 1 indicating a strong disagreement. It is apparent from the figure that Turkey is, once again, a remarkable outlier - its society displays much less respect for women's rights than other EU28 and the Balkan countries. The rest of the Balkan countries also show a significant low regard for women's rights, as measured by this question, with the exception of Croatia, and, to some extent, Montenegro. Our paper does not focus on women rights, but the fact that many of the countries in the region score low in the defense of these values is, in our view, a factor that can potentially explain the existence of significantly large gender gaps in their labor markets. ${ }^{5}$

Turning to the microdata used in our calculations, Table 2 shows the evolution of the gender gaps for each country over the periods considered here. In terms of Labor Force Participation, the most salient feature is that there is a very large gender gap in labor force participation in all countries. This gap is largest in Turkey both in the first year (63.4\%) and the last year (55\%). Second, it is also worth noting that the labor force participation gap decreases to some extent in most countries, especially in Kosovo, where it drops by more than half. In Self-employment, the gap is also apparent in all countries, with the exception of Croatia, where the gender gap is negative in both years. Interestingly, the only country where we see a marked increase in this gap over time is Turkey. Kosovo has the largest gaps in both years, with an astonihing figure of $94 \%$. Finally, there is also a very clear gender gap in the category Employers. The gap closes during these two periods in most countries, especially in Albania and it only increases in Kosovo and Montenegro. Turkey once again has the largest gap both in the first and last year of the sample.

\footnotetext{
${ }^{4}$ See http://www.worldvaluessurvey.org/wvs.jsp

${ }^{5}$ A similar question from the EBRD-World Bank Life In Transition Survey 2016, covering all Eastern European countries, asking men and women to agree or disagree with the question 'It is better for everyone involved if the man earns the money and the woman takes care of the home and children" shows all countries in the region have a level of agreement above 50\% (Albania: 53.35\%, Montenegro: 59.85\%, Kosovo: 57.65\%, Serbia: $60.7 \%$, FYR Macedonia: 60.15\%, Croatia: $42.85 \%$ ). Source: EBRD-World Bank Life In Transition Survey 2016.
} 


\section{$2.3 \quad$ Statistics by age group}

Tables 3-5 report the existing gender gaps in the labor force participation, employers and self-employed for three different age groups. We split our sample in three age groups: 15-35, 36-50, and above 50. Table 3 shows that there exist significant gender gaps against women in labor force participation in the majority of age groups, with the largest gaps being in the older age group.

In Table 4 it is again apparent that there are gender gaps in employers in almost all age groups. In this case, the largest gaps are among the middle age group, on average. Finally, Table 5 shows the gender gaps by age groups in self-employment. Interestingly, in this case the average gap is largest for the youngest group.

\section{Framework}

\subsection{Summary of the theoretical model}

In this section, we present a brief summary of the model developed in Cuberes and Teignier (2016). Their paper develops a general equilibrium occupational choice model where agents are endowed with a random entrepreneurship skill, based on which they decide to work as either employers, self-employed, or workers. ${ }^{6}$ Agents choosing to become firm workers earn the equilibrium wage rate $w$-which it is assumed to be independent of their entrepreneurial talent-, while entrepreneurs earn the profits generated by the firm they manage. An agent with entrepreneurial talent or productivity level $x$ who chooses to become an employer hires $n(x)$ units of labor and $k(x)$ units of capital. He/she then produces $y(x)$ units of output and earns profits $\pi(x)=y(x)-r k(x)-w n(x)$, where the price of the homogeneous good is normalized to one. As in Lucas (1978) and Buera and Shin (2011), the production function is given by

$$
y(x)=x\left(k(x)^{\alpha} n(x)^{1-\alpha}\right)^{\eta}
$$

where $\alpha \in(0,1)$ and $\eta \in(0,1)$. The parameter $\eta$ measures the span of control of entrepreneurs and, since it is smaller than one, the entrepreneurial technology involves an element of diminishing returns. On the other hand, an agent with talent $x$ who chooses to become self-employed uses the amount of capital $\tilde{k}(x)$, produces $\tilde{y}(x)$ units of output and earns profits $\tilde{\pi}(x)=\tilde{y}(x)-r \tilde{k}(x)$. The technology he or she operates is

$$
\tilde{y}(x)=\tau x \tilde{k}(x)^{\alpha \eta}
$$

where $\tau$ is the self-employed productivity parameter. One interpretation of this parameter is

\footnotetext{
${ }^{6}$ Although strictly speaking they are different status of employment, we use the work occupations to refer to the categories workers, self-employed, and employers following Lucas (1978).
} 
that self-employed workers have to spend a fraction of their time on management tasks, which would imply that $\tau$ is equal to the fraction of time available for work to the power $(1-\alpha) \eta$. As explained below, we estimate this parameter to match the average fraction of self-employed in the data.

Figure 2 plots the payoff of the three occupations at each talent level. For the employers and self-employed, the profit functions, $\pi$, use the subscripts $e$ and $s$, respectively. It shows that in this model agents with the highest entrepreneurship skill (those with a talent equal or larger than $z_{2}$ ) optimally choose to become employers, whereas those with the least skill become workers (with a talent lower than $z_{1}$ ), leaving the self-employed occupation to agents with intermediate skill levels.

We also allow for the possibility of the so-called out-of-necessity entrepreneurs, who choose this occupation because they had no other choice. To capture this phenomenon, in the model, a fraction $1-\theta$ of both males and females are not allowed to become workers and become self-employed. The parameter $\theta$ is estimated for each country to match the overall share of self-employed workers, and we find it takes a value below 1 for Albania, Serbia, and Turkey (and equal to 1 for the rest of countries, indicating that all agents with low entrepreneurial skills become workers).

The model assumes that men and women are identical in terms of their managerial skills. However, women are subject to several exogenous constraints in the labor market. First, a fraction $1-\mu$ of women who would like to be employers are excluded from this occupation, while a a fraction $(1-\mu)\left(1-\mu_{o}\right)$ of women are also excluded from self-employment. On top of that, a fraction $1-\lambda$ of women are entirely excluded from participating in the labor market. Importantly, in our framework all women have the same probability of facing these constraints, implying that there is no positive or negative selection into participation or entrepreneurship. Admittedly, the effects of the gender gaps on income would be smaller if excluded women had, on average, lower talent, while they would be larger if they had higher talent.

The restriction on the female labor market participation mechanically results in a reduction in output per capita because the amount of productive inputs falls. The restrictions altering the occupational choice, on the other hand, reduce the average talent of entrepreneurs, which leads to a fall in productivity and income per capita. The intuition behind the reduction in productivity is as follows. Assume a woman with very good management skills happens to be banned from becoming an employer. The model then implies that a less skilled man will take her position and become the manager of a firm. Notice that, if this man has a lower managerial skill than the woman who is not allowed to become a manager, he will run a smaller firm - due to the nature of the span-of-control technology. This would then have general equilibrium implications in terms of the amount of output produced, wages and firms' profits. It is is easy to show that output/income per worker and per capita would be lower in 
this economy as a result of this restriction. ${ }^{7}$ We measure this loss by taking the ratio between output per capita with no gender gaps and the corresponding output per capita given the observed gender gaps. ${ }^{8}$

\subsection{Model Simulation}

To simulate the model, we use a Pareto function for the talent distribution, as in Lucas (1978) and Buera et al. (2011). In particular, the cumulative distribution of talent is given by

$$
\Gamma(x)=1-B^{\rho} x^{-\rho}, x \geq 0,
$$

where $\rho, B>0$.

In terms of parameter values, $B$ is normalized to $1, \eta$ is set to 0.79 from Buera and Shin (2011), the capital-output elasticity parameter $\alpha$ is set to 0.114 in order to get a capital income share of $30 \%, \rho$ is set to 6.5 to match the fraction of employers in the OECD countries (which is $4.5 \%$ on average), and, finally, $\tau$ is chosen to match the fraction of self-employed workers in the OECD countries (which is $10.8 \%$ on average). When computing the numerical results in the next two subsections, we let the capital stock adjust to its steady-state value, which we compute using a gross interest rate of 0.125 . This is consistent with a depreciation rate of 0.075 and an intertemporal discount factor of 0.05 in a continuous-time model.

For each country in our sample, we also need the values of the gender frictions $\left(\lambda, \mu, \mu_{o}\right)$, which we compute using data on male and female labor force participation, share of employers and share of self-employed. The average values obtained are 0.68, 0.42 and 0.21 respectively, implying that $32 \%$ of women are excluded from the labor force, $58 \%$ of the women on the labor force cannot become employers, and $47 \%$ cannot become self employed either. The country specific values are presented in Table 6 .

\section{Numerical results}

\subsection{Aggregate effects of the gender gaps in the Balkans and Turkey}

Figure 3 and Table 6show the income per capita losses with respect to a counterfactual scenario without gender gaps for each of the countries in our sample, as well as the corresponding average for the EU28 for comparison. ${ }^{9}$ The columns 2-5 of Table 6 display the estimated gender frictions or barriers, while column 6 shows the estimated loss in income per capita due to the three frictions and column 7 the income loss due to the gender frictions in employership and self-employment (i.e. due to the $\left(\mu, \mu_{o}\right)$ frictions). The difference between these last two

\footnotetext{
${ }^{7}$ See Cuberes and Teignier (2016) for more details on this result.

${ }^{8}$ Naturally, in this model, total output equals total income.

${ }^{9}$ In all the results that follow we refer losses in terms of income per capita.
} 
columns - not displayed here - would correspond to the income loss generated by the gaps in the labor force participation.

As we can see in the table, Turkey in 2007 has the highest per-capita income loss, 34.4\%, followed by the same country in 2015 , with a loss of $30.3 \%$. Croatia is the country with the smallest income loss in both the initial and final year, with a 11.1 and $10.1 \%$ loss, respectively. In column 7 we can see that Kosovo and Turkey are the countries displaying the highest income loss due to gender frictions in entrepreneurship, above $7 \%$ in all cases. Croatia is again the country with the smallest loss from the entrepreneurship gaps (around $4 \%$ in both years).

\subsection{Effects of the gender gaps in the Balkans and Turkey by age groups}

The purpose of this section is to to decompose the total income loss in order to calculate the contribution of each age group. As argued in World Bank (2012), gender gaps are likely to vary across age groups and this may have important implications for the future evolution of the labor market and the evolution of the associated productivity losses. ${ }^{10}$

To carry out the age group decomposition of the total income loss, we first need to calculate a counterfactual set of gender frictions for each age group. In particular, to get the fraction of the total income loss due to a particular age group, we compute what would the aggregate gender friction be if all the gender frictions were zero except for that particular age group.

For example, if we had two age groups, the aggregate employer's gap, denoted by $\mu$, would be defined as follows:

$$
\mu \equiv \frac{E_{f}^{\text {all }} / L_{f}^{\text {all }}}{E_{m}^{\text {all }} / L_{m}^{\text {all }}}=\frac{\frac{E_{f}^{1}+E_{f}^{2}}{L_{f}^{1}+L_{f}^{2}}}{\frac{E_{m}^{1}+E_{m}^{2}}{L_{m}^{1}+L_{m}^{2}}},
$$

where $E$ stands for number of employers and $L$ represents the labor force. The subindexes $f, m$ denote females and males, respectively, while the superindexes 1,2 represent the first and second age groups, respectively. Finally, the superindex all corresponds to the sum of the two age groups. We can then rewrite $\mu$ in terms of the employers' friction of each group:

$$
\mu=\frac{\mu_{1} \frac{E_{m}^{1}}{L_{m}^{1}} \frac{L_{f}^{1}}{L_{f}^{a l l}}+\mu_{2} \frac{E_{m}^{2}}{L_{m}^{2}} \frac{L_{f}^{2}}{L_{f}^{a l l}}}{E_{m}^{\text {all }} / L_{m}^{\text {all }}}
$$

where $\mu_{i}=\frac{E_{f}^{i} / L_{f}^{i}}{E_{m}^{i} / L_{m}^{i}}, i=1,2$. For instance. to compute the income loss due to the age group 1 , we would proceed in two stages. First, we would set $\mu_{2}=1$ in equation (4) Second, we would use the implied $\mu$ to calculate the aggregate income loss.

\footnotetext{
${ }^{10}$ For a study of the changing demographic profile of women in Turkey, see Dayığlu and Kırdar (2010).
} 
For $n$ groups, we would have:

$$
\mu=\frac{\sum_{j=1}^{n} \mu_{j} \frac{E_{m}^{j}}{L_{m}^{j}} \frac{L_{f}^{j}}{L_{f}^{\text {all }}}}{E_{m}^{\text {all }} / L_{m}^{\text {all }}},
$$

This formula illustrates the fact that the impact of the gender gap in a given age group depends not only on the magnitude of this gap but also on the weight of the age group in the female labor force.

Table 7 shows the fraction of the total income loss due to gender gaps of each age group. In the first row, for instance, we can see the decomposition of the total income loss in Albania for the latest available year: $36 \%$ of the total loss is due to gender gaps in the age group 15-35, $28 \%$ is due to gender gaps in the age group 36-50, and 36\% to gender gaps in the age group above 50. The main takeaway from this table is that the average income losses (the last row of the column) are, perhaps surprisingly, spread very equally across age groups. Still, some countries have losses more concentrated in specific age groups. For example, in Turkey, $41 \%$ of the loss is associated to the young group in the first year. In Montenegro, in the second year, $42 \%$ of the loss is accrued to the 36-50 age group. In Albania, on the other hand, $44 \%$ of the loss in the first year can be attributed to the older age group.

Figure 4 plots for each country the income loss generated by each of the three age groups in the first and latest available year. The total height is the total income loss due to all gender gaps and each bar is divided in three areas corresponding to the three age group.

The results of this section show that, in the Balkans and Turkey during the 2000s, the gender gaps in the labor market that we study, are prevalent across all age groups. One possible implication of this finding is that policies to reduce these gaps should be across the board and not focus on any specific age group.

\section{Concluding remarks}

In this paper we calculate the gender gaps in labor force participation, employers and selfemployed for several Balkan countries (Albania, Bosnia and Herzegovina, Croatia, Kosovo, Macedonia, Montenegro, and Serbia) and Turkey. Our survey data reveal very large gaps in most countries in the two years studied. This reflects a puzzling underrepresentation of women in these countries, particulary given their relatively high income per capita. When we conduct our analysis for different age groups, we find that these gender inequalities are present in all age groups, with the middle-age group displaying the highest inequality in terms of employers share. The older age group has the largest gap in labor force participation, whereas the middle-age group displays the largest gender gaps in self-employment.

We then proceed to provide an estimate of the aggregate losses in terms of income per 
capita using the occupational choice model proposed in Cuberes and Teignier (2016). Our results suggest sizable income per capita losses. On average, about $20 \%$ of the potential income per capita is lost due to the gender gaps studied here. Of this loss, about a third can be attributed to the low numbers of women working as employers and/or self-employed. For comparison purposes, Cuberes and Teignier (2016), using ILO data, obtain an average income loss of around 10\% in non-OECD European countries, while only Middle East and North Africa, as well as South Asia, have larger average income losses. Taking into account that the weight of each age group in the total population is different, we find that the aggregate costs associated to each age group are quite similar on average. We also find that, on average, in the period studied here, these gender gaps are quite persistent i.e. they have not decreased much. Our results suggest that there would be substantial gains in formulating and implementing policies that help reduce these gaps, which are otherwise unlikely to correct themselves without some type of policy intervention. At the same time, the fact that the gaps are similar across all age groups suggests that such a policy should be across-the-board, i.e. it should aim all age groups, probably by aiming at providing the right incentives at each age.

It is important to keep in mind that the losses we compute are for market output only and does not include women's contribution in unpaid tasks related to home production or the informal economy. Admittedly, individuals who do not participate in the formal labor market are likely to produce more non-market output than those who participate. Cuberes and Teignier (2018), however, show that the presence of a household sector leads to larger losses due to entrepreneurship gender gaps by reducing the amount of full-time employment. At the same time, as stated above, our quantitative results assume that men and women have the same distribution of managerial skills. Moreover, we assume that there are no restrictions in the capital market and so capital is assigned to firms in a competitive way. If women had lower skills than men, and/or had less access to capital than men, then our framework we may be overestimating the effects of the entrepreneurship gender gaps. On the other hand, we could also be underestimating the effects if, for example, gender gaps were actually larger in sectors where managerial ability is more important for production or females talent was complementary to the males one. Similarly, our framework assumes that all women are equally likely to be excluded from the labor market and from entrepreneurship. If there was positive selection, we would be overestimating the effects, while we would be underestimating them if the selection was negative. Quantifying the importance of these potential biases is left for future research. 


\section{References}

Anderson, D. J., Binder, M., and Krause, K., 2002. "The Motherhood Wage Penalty: Which Mothers Pay It and Why?" American Economic Review, Papers and Proceedings, vol. 92, No 2, pp 354-358.

Buera, F. J., Shin, Y., 2011. "Self-Insurance vs. Self-Financing: A Welfare Analysis of the Persistence of Shocks." Journal of Economic Theory 146, 845-862.

Buera, F. J., Kaboski, J. P., Shin, Y., 2011. "Finance and Development: A Tale of Two Sectors." American Economic Review 101 (5), 1964-2002.

Cavalcanti, T., and Tavares, J., 2016. "The Output Cost of Gender Discrimination: A Model-Based Macroeconomic Estimate." The Economic Journal, vol. 126, Issue 590, pp. 109-134.

Cuberes, D., and Teignier, M., 2016. "Aggregate Costs of Gender Gaps in the Labor Market: A Quantitative Estimate." Journal of Human Capital, vol. 10, Issue 1.

Cuberes, D., and Teignier, M., 2018. "Macroeconomic Costs of Gender Gaps in a Model with Household Production and Entrepreneurship." B.E. Journal of Macroeconomics, vol. 18, Issue 1.

Dayığlu, M., and Kırdar, M.G., 2010. "Determinants of and Trends in Labor Force Participation of Women in Turkey." Welfare and Social Policy Analytical Work Program Working Paper Number:5. State Planning Organization of the Republic of Turkey and World Bank, 2010.

ECATSD (2017). DATALIB: ECAPOV Ex-post Harmonization. [country names/years (separated by semi-colon)]. As of (August 2017)

European Parliament Think Tank, 2017. "Rights and empowerment of women in the Western Balkans." Briefing, June 2017. European Parliament.

Galor, O., and Weil, D. N., 1996. "The Gender Gap, Fertility, and Growth." American Economic Review 85(3), 374-387.

Hsieh, C., Hurst, E., Jones, C., and Klenow, P., 2013. "The Allocation of Talent and U.S. Economic Growth." NBER Working Paper No. 18693.

ILO (2014), "Global Employment Trends."

Lucas Jr., R. E., 1978. On the Size Distribution of Business Firms. The Bell Journal of Economics 9(2), 508-523.

World Bank, 2012. "World Development Report 2012: Gender Equality and Development."

World Bank Group and Vienna Institute for International Economic Studies, 2017. "Western Balkans Labor Market Trends 2017.” Report Number 113922. 


\section{Appendix I: data sources}

Institute of Statistics of Albania. Albania Living Standards Measurement Survey 2012. World Bank ECAPOV harmonization.

Institute of Statistics of Albania. Albania Living Standards Measurement Survey 2008. World Bank ECAPOV harmonization.

Agency for Statistics of Bosnia and Herzegovina, Federal Institute of Statistics and Republic Institute of Statistics of the Republic of Srpska. Labor Force Survey 2006. World Bank ECAPOV harmonization.

Agency for Statistics of Bosnia and Herzegovina, Federal Institute of Statistics and Republic Institute of Statistics of the Republic of Srpska. Labor Force Survey 2013. World Bank ECAPOV harmonization.

Croatian Bureau of Statistics, Household Budget Survey 2004. World Bank ECAPOV harmonization.

Croatian Bureau of Statistics, Household Budget Survey 2009. World Bank ECAPOV harmonization

Kosovo Agency for Statistics. Household Budget Survey 2006. World Bank ECAPOV harmonization

Kosovo Agency for Statistics. Household Budget Survey 2012. World Bank ECAPOV harmonization

Kosovo Agency for Statistics. Household Budget Survey 2015. World Bank ECAPOV harmonization

Statistical office of Montenegro. Household Budget Survey 2007. World Bank ECAPOV harmonization

Statistical office of Montenegro. Household Budget Survey 2015. World Bank ECAPOV harmonization

Statistical Office of the Republic of Serbia. Household Budget Survey 2006. World Bank ECAPOV harmonization

Statistical Office of the Republic of Serbia. Household Budget Survey 2015. World Bank ECAPOV harmonization

Turkish Statistical Institute. Household Income and Consumption Expenditure Survey. 2007 World Bank ECAPOV harmonization

Turkish Statistical Institute. Household Income and Consumption Expenditure Survey. 2015 World Bank ECAPOV harmonization 


\section{Appendix II: country abbreviations}

Albania (ALB), Austria (AUT), Belgium (BEL), Bulgaria (BGR), Bosnia and Herzegovina (BIH), Cyprus (CYP), Czech Republic (CZE), Germany (DEU), Denmark (DNK), Spain (ESP), Estonia (EST), Finland (FIN), France (FRA), United Kingdom (GBR), Greece (GRC), Croatia (HRV), Hungary (HUN), Ireland (IRL), Italy (ITA), Lithuania (LTU), Luxembourg (LUX), Latvia (LVA), Macedonia (MKD), Malta (MLT), Montenegro (MNE), Netherlands (NLD), Poland (POL), Portugal (PRT), Serbia (SRB), Slovakia (SVK), Slovenia (SVN), Sweden (SWE), and Turkey (TUR). 


\section{Figures}

Figure 1: Gender gaps and gender values in EU28, the Balkans, and Turkey (year=2010)
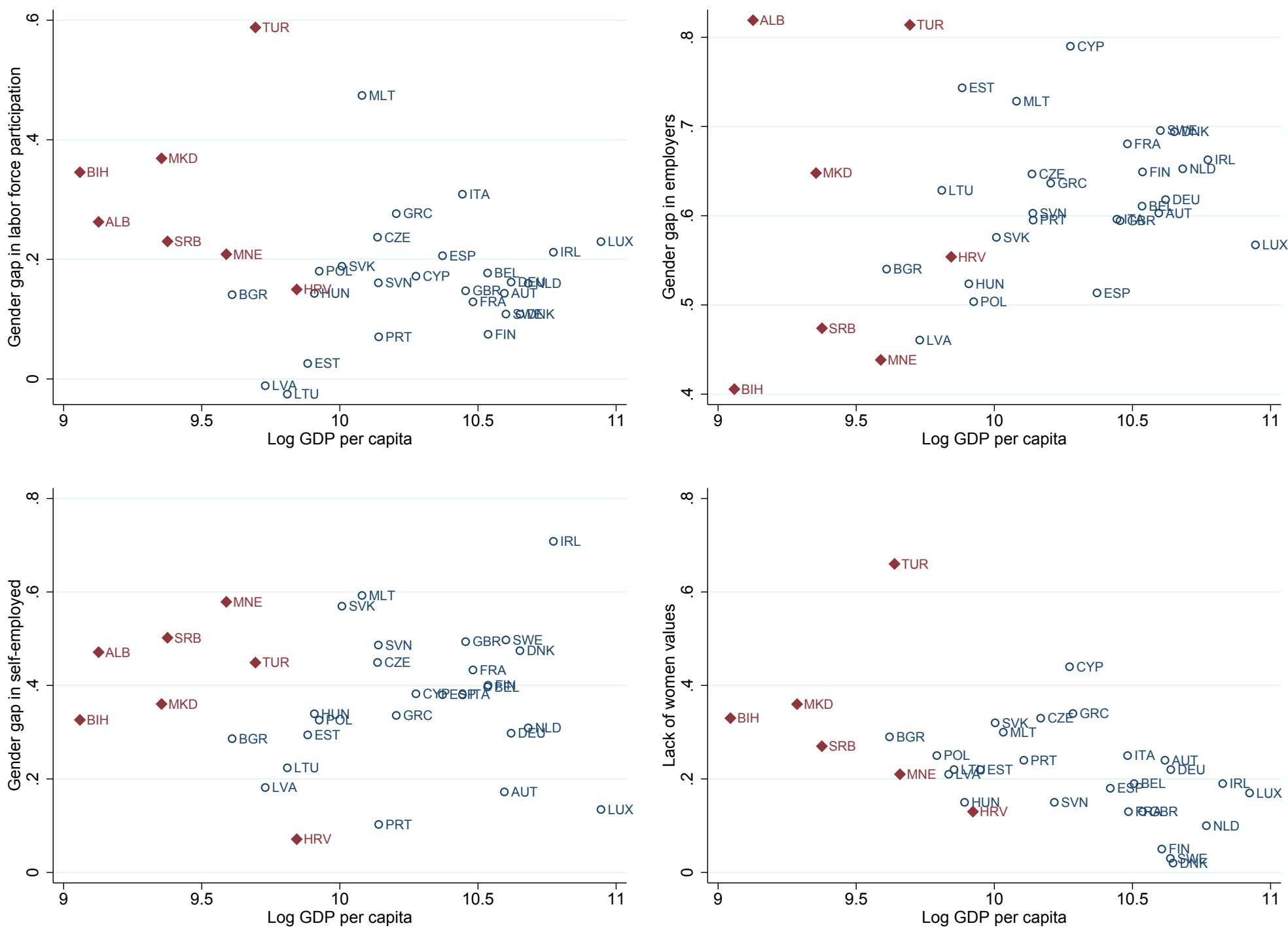
Figure 2: The occupational map

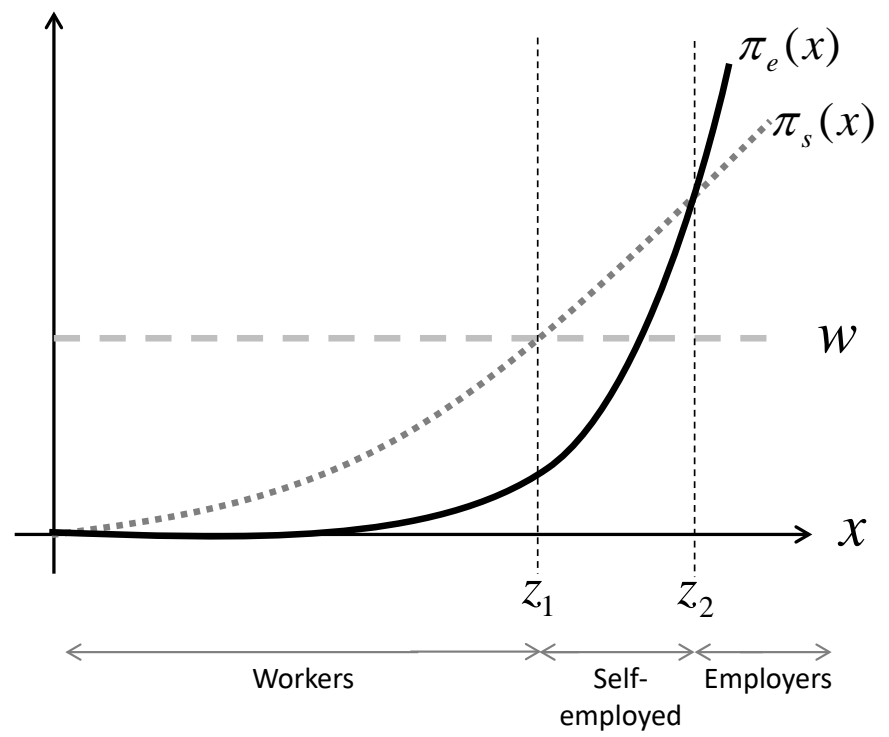

Figure 3: Income per capita losses and productivity losses due to gender gaps, by country
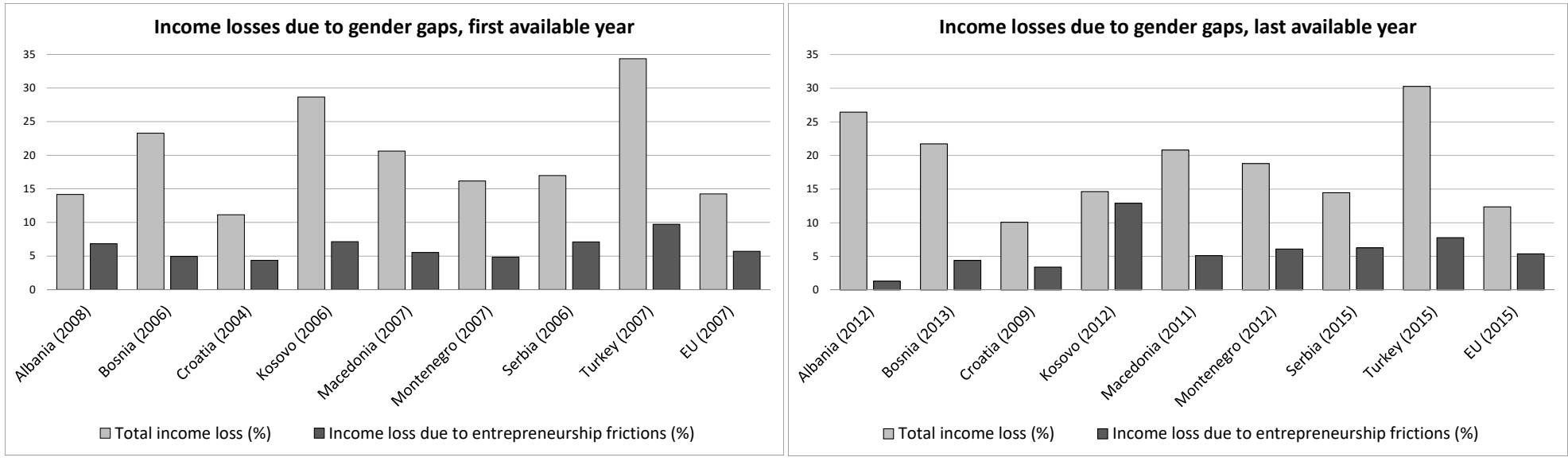

Figure 4: Income losses due to gender gaps, by age group
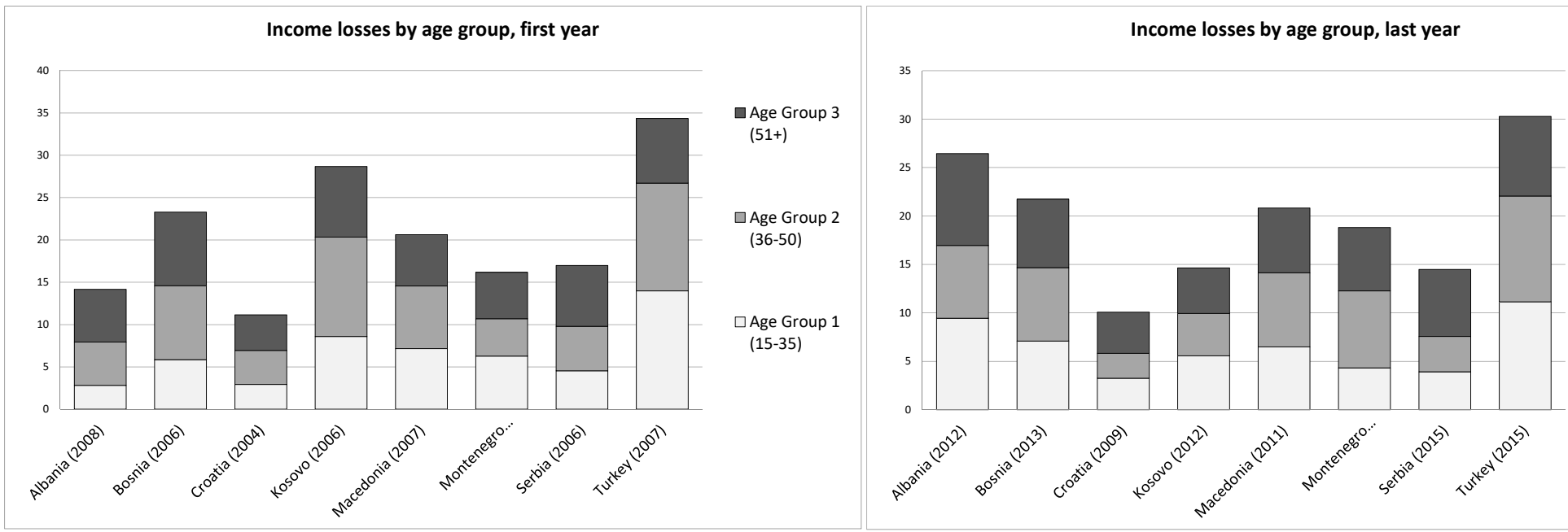


\section{Tables}

Table 1: Average Gender Gaps in the Labor Market in EU28 in 2010 (\%)

\begin{tabular}{c|c|c|c}
\hline & Employers & Self-Employed & Labor force part. \\
\hline EU28 & 62 & 37.1 & 16.1 \\
Balkans and Turkey & 59.3 & 39.4 & 30.8 \\
\hline
\end{tabular}

Datasource: World Bank ECAPOV (Balkans and Turkey) and ILO (EU28).

Table 2: Gender Gaps in the labor market (\%)

\begin{tabular}{c|cc|cc|cc|cc}
\hline & \multicolumn{2}{|c|}{ Years } & \multicolumn{2}{c|}{ Labor force } & Self-Employed & \multicolumn{2}{c}{ Employers } \\
\hline & $t=1$ & $t=2$ & $t=1$ & $t=2$ & $t=1$ & $t=2$ & $t=1$ & $t=2$ \\
\hline Albania & 2008 & 2012 & 22.8 & 52.4 & 34.7 & 40.1 & 53.3 & 9.5 \\
Bosnia and Herzegovina & 2006 & 2013 & 40.9 & 38.1 & 39 & 36.1 & 53.7 & 48.3 \\
Croatia & 2004 & 2009 & 15 & 14.3 & -3.1 & -52.5 & 52.9 & 44.9 \\
Kosovo & 2006 & 2012 & 53.2 & 16.4 & 94 & 94.3 & 57 & 87.8 \\
Macedonia & 2007 & 2011 & 34.3 & 35.1 & 75 & 67.6 & 57.2 & 53.6 \\
Montenegro & 2007 & 2012 & 25.2 & 25.4 & 51.1 & 46.7 & 51 & 80.7 \\
Serbia & 2006 & 2015 & 23.3 & 20.8 & 56.7 & 54.8 & 72.7 & 58.1 \\
Turkey & 2007 & 2015 & 63.4 & 55 & 41.3 & 45.8 & 89.6 & 73.7 \\
EU28 & 2007 & 2015 & 19.5 & 15.8 & 40.7 & 39 & 61.2 & 58.2 \\
\hline Balkans and Turkey average & & & $\mathbf{3 4 . 8}$ & $\mathbf{3 2 . 2}$ & $\mathbf{4 8 . 6}$ & $\mathbf{4 1 . 6}$ & $\mathbf{6 1}$ & $\mathbf{5 7 . 1}$ \\
\hline
\end{tabular}

Datasource: World Bank ECAPOV (Balkans and Turkey) and ILO (EU28).

Table 3: Gender Gaps in Labor Force Participation by Age (\%)

\begin{tabular}{|c|c|c|c|c|c|c|}
\hline & \multicolumn{2}{|c|}{ Age $15-35$} & \multicolumn{2}{|c|}{ Age $36-50$} & \multicolumn{2}{|c|}{ Age 51 and above } \\
\hline & $t=1$ & $t=2$ & $t=1$ & $t=2$ & $t=1$ & $t=2$ \\
\hline Albania & 16.6 & 53.9 & 11.1 & 40.4 & 43.3 & 63.6 \\
\hline Bosnia and Herzegovina & 35.3 & 39.2 & 40 & 33.9 & 46.5 & 42.7 \\
\hline Croatia & 15.3 & 22.1 & 4.8 & -8.8 & 28.8 & 31.1 \\
\hline Kosovo & 26.5 & 40.5 & 70.7 & 15.6 & 86.1 & -24 \\
\hline Macedonia & 32.7 & 31.6 & 30.4 & 33.2 & 43.1 & 43.4 \\
\hline Montenegro & 23.8 & 23 & 17.5 & 25.6 & 25.6 & 42.1 \\
\hline Serbia & 21.6 & 19.1 & 11.9 & 7.2 & 37.3 & 36.2 \\
\hline Turkey & 60.8 & 52 & 68.6 & 54.4 & 59.7 & 62.8 \\
\hline Average & 29.1 & 35.2 & 31.9 & 25.2 & 46.3 & 37.2 \\
\hline
\end{tabular}


Table 4: Gender Gaps in Employers by Age (\%)

\begin{tabular}{|c|c|c|c|c|c|c|}
\hline & \multicolumn{2}{|c|}{ Age 15-35 } & \multicolumn{2}{|c|}{ Age $36-50$} & \multicolumn{2}{|c|}{ Age 51 and above } \\
\hline & $t=1$ & $t=2$ & $t=1$ & $t=2$ & $t=1$ & $t=2$ \\
\hline Albania & 5.7 & 8.8 & 59.7 & 7.1 & 51 & 20.9 \\
\hline Bosnia and Herzegovina & 32.1 & 48 & 50.1 & 44.7 & 59.9 & 54.2 \\
\hline Croatia & 20.9 & 18.5 & 68.3 & 60.6 & 39.1 & 35.1 \\
\hline Kosovo & 69 & 61.1 & 37.9 & 97.3 & -53.5 & 94.1 \\
\hline Macedonia & 61.6 & 46.1 & 54.1 & 50.8 & 60.3 & 60.5 \\
\hline Montenegro & 89 & -21 & 31.7 & 90.6 & 34.4 & 71.1 \\
\hline Serbia & 61 & 79.5 & 74 & 51.1 & 75.4 & 53.4 \\
\hline Turkey & 93.3 & 87.2 & 88.6 & 65.6 & 85.3 & 76.2 \\
\hline Average & 54 & 41 & 58.1 & 58.5 & 44 & 58.2 \\
\hline
\end{tabular}

Datasource: World Bank ECAPOV.

Table 5: Gender Gaps in Self-Employed by Age (\%)

\begin{tabular}{|c|c|c|c|c|c|c|}
\hline & \multicolumn{2}{|c|}{ Age $15-35$} & \multicolumn{2}{|c|}{ Age $36-50$} & \multicolumn{2}{|c|}{ Age 51 and above } \\
\hline & $t=1$ & $t=2$ & $t=1$ & $t=2$ & $t=1$ & $t=2$ \\
\hline Albania & 9.6 & 43.4 & 25.6 & 41.9 & 48.6 & 34.8 \\
\hline Bosnia and Herzegovina & 34.9 & 48 & 36.1 & 35.7 & 38.1 & 31.3 \\
\hline Croatia & 1 & 25.6 & -17.8 & -43 & -9.4 & -90.5 \\
\hline Kosovo & 99.23 & 93.8 & 79.3 & 91.8 & 100 & 97.9 \\
\hline Macedonia & 71.7 & 67.3 & 72.9 & 62.8 & 80.9 & 72.6 \\
\hline Montenegro & 70.9 & 57.5 & 65.6 & 40.4 & 6.2 & 50.3 \\
\hline Serbia & 69.5 & 52.3 & 55.6 & 51.9 & 47.5 & 32.8 \\
\hline Turkey & 26.8 & 35.3 & 37.1 & 27.2 & 52.1 & 59.3 \\
\hline Average & 48 & 53 & 44.3 & 38.6 & 45.5 & 36.1 \\
\hline
\end{tabular}


Table 6: Long-Run income per capita losses due to gender gaps, by country

\begin{tabular}{|c|c|c|c|c|c|c|}
\hline & Year & $\begin{array}{c}\begin{array}{c}\text { LFP } \\
\text { friction }\end{array} \\
(1-\lambda)\end{array}$ & $\begin{array}{c}\text { Employer's } \\
\text { friction } \\
(1-\mu) \\
\end{array}$ & $\begin{array}{l}\begin{array}{c}\text { Self-employed's } \\
\text { friction }\end{array} \\
(1-\mu)\left(1-\mu_{o}\right)\end{array}$ & $\begin{array}{c}\text { Total income } \\
\text { loss from } \\
\text { Gender Gaps } \\
(\%) \\
\end{array}$ & $\begin{array}{c}\text { Income loss } \\
\text { due to } \\
\text { Entrepr. Gap } \\
(\%) \\
\end{array}$ \\
\hline \multirow{2}{*}{ Albania } & 2008 & 0.17 & 0.53 & 0.38 & 14.16 & 6.82 \\
\hline & 2012 & 0.52 & 0.10 & 0.10 & 26.44 & 1.32 \\
\hline \multirow{2}{*}{ Bosnia and Herzegovina } & 2006 & 0.41 & 0.54 & 0.44 & 23.28 & 4.94 \\
\hline & 2013 & 0.38 & 0.48 & 0.40 & 21.72 & 4.41 \\
\hline \multirow{2}{*}{ Croatia } & 2004 & 0.15 & 0.53 & 0.38 & 11.15 & 4.36 \\
\hline & 2009 & 0.14 & 0.45 & 0.00 & 10.07 & 3.41 \\
\hline \multirow{2}{*}{ Kosovo } & 2006 & 0.51 & 0.57 & 0.57 & 28.67 & 7.13 \\
\hline & 2012 & 0.05 & 0.88 & 0.88 & 14.64 & 12.9 \\
\hline \multirow{2}{*}{ Macedonia } & 2007 & 0.34 & 0.57 & 0.57 & 20.62 & 5.53 \\
\hline & 2011 & 0.35 & 0.54 & 0.54 & 20.82 & 5.11 \\
\hline \multirow{2}{*}{ Montenegro } & 2007 & 0.25 & 0.51 & 0.51 & 16.17 & 4.84 \\
\hline & 2012 & 0.29 & 0.64 & 0.54 & 18.81 & 6.09 \\
\hline \multirow{2}{*}{ Serbia } & 2006 & 0.23 & 0.73 & 0.62 & 16.98 & 7.1 \\
\hline & 2015 & 0.19 & 0.58 & 0.56 & 14.48 & 6.28 \\
\hline \multirow{2}{*}{ Turkey } & 2007 & 0.62 & 0.90 & 0.54 & 34.36 & 9.72 \\
\hline & 2015 & 0.54 & 0.74 & 0.53 & 30.28 & 7.79 \\
\hline \multirow{2}{*}{ EU28 } & 2007 & 0.19 & 0.61 & 0.47 & 14.26 & 5.7 \\
\hline & 2015 & 0.16 & 0.58 & 0.45 & 12.37 & 5.38 \\
\hline
\end{tabular}

Source: own calculations using data from World Bank ECAPOV (Balkans and Turkey) and ILO (EU28).

Table 7: Income loss decomposition by age group

\begin{tabular}{c|cccccc}
\hline (\% of country's & \multicolumn{2}{|c}{ Age $15-35$} & \multicolumn{2}{c}{ Age $36-50$} & \multicolumn{2}{c}{ Age 51 and above } \\
\cline { 2 - 7 } total income loss) & $t=1$ & $t=2$ & $t=1$ & $t=2$ & $t=1$ & $t=2$ \\
\hline Albania & 19.95 & 35.73 & 36.07 & 28.4 & 43.98 & 35.87 \\
Bosnia and Herzegovina & 25.17 & 32.6 & 37.51 & 34.89 & 37.32 & 32.51 \\
Croatia & 26.29 & 32.21 & 36.05 & 25.54 & 37.66 & 42.25 \\
Kosovo & 29.96 & 38.01 & 40.96 & 29.88 & 29.08 & 32.11 \\
Macedonia & 34.72 & 31.13 & 35.92 & 36.75 & 29.36 & 32.12 \\
Montenegro & 38.84 & 22.91 & 27.29 & 42.31 & 33.87 & 34.78 \\
Serbia & 26.79 & 27.09 & 30.94 & 25.15 & 42.27 & 47.77 \\
Turkey & 40.71 & 36.76 & 37.03 & 36.09 & 22.26 & 27.15 \\
\hline Average & $\mathbf{3 0 . 3}$ & $\mathbf{3 2 . 0 5}$ & $\mathbf{3 5 . 2 2}$ & $\mathbf{3 2 . 3 8}$ & $\mathbf{3 4 . 4 3}$ & $\mathbf{3 5 . 5 7}$ \\
\hline
\end{tabular}

Source: own calculations using data from World Bank ECAPOV. 